\title{
Electrochemical Properties of a Zirconia Membrane with a Lanthanum Manganate-Zirconia Composite Electrode and its Oxygen Permeation Characteristics by Applied Currents
}

\author{
Ji Young Park*, Noh Hyun Jung**, Doh Won Jung****, \\ Sung-Jin Ahn $* * * *$, and Hee Jung Park $(1) * * * * * ;$ \\ ${ }^{*}$ School of Nano \& Materials Science and Engineering, Kyungpook National University, Sangju 37224, Korea \\ **Kceracell, Boksu-myeon, Geumsan 32702, Korea \\ ***Material Research Center, Samsung Advanced Institute of Technology (SAIT), Suwon 16678, Korea \\ ****Department of Materials Science and Engineering, Dankook University, Cheonan 31116, Korea
}

(Received March 2, 2019; Revised March 11, 2019; Accepted March 12, 2019)

\begin{abstract}
An electrochemical oxygen permeating membrane (OPM) is fabricated using $\mathrm{Zr}_{0.895} \mathrm{Sc}_{0.095} \mathrm{Ce}_{0.005} \mathrm{Gd}_{0.005} \mathrm{O}_{2-\delta}$ ( $\mathrm{ScCeGdZ)}$ as the solid electrolyte and $\mathrm{aLa}_{0.7} \mathrm{Sr}_{0.3} \mathrm{MnO}_{3}$-bScCeGdZ composite (LZab, electrode) as the electrode. The crystal phase of the electrode and the microstructure of the membrane is investigated with X-ray diffraction and scanning electron microscopy. The electrochemical resistance of the membrane is examined using 2-p ac impedance spectroscopy, and LZ55 shows the lowest electrode resistance among LZ82, LZ55 and LZ37. The oxygen permeation is studied with an oxygen permeation cell with a zirconia oxygen sensor. The oxygen flux of the OPM with LZ55 is nearly consistent with the theoretical value calculated from Faraday's Law below a critical current. However, it becomes saturated above the critical current due to the limit of the oxygen ionic conduction of the OPM. The OPM with LZ55 has a very high oxygen permeation flux of $\sim 3.5 \times 10^{-6} \mathrm{~mol} / \mathrm{cm}^{2} \mathrm{~s}$ in I $=1.4 \mathrm{~A} / \mathrm{cm}^{2}$.
\end{abstract}

Key words : Zirconia, Composite Electrode, Electrochemical property, Oxygen permeation

\section{Introduction}

$\mathrm{T}$ he electrochemical dense ceramic membranes with oxygen permeation have attracted our attention due to their various applications: separation of oxygen from air, conversion of natural gas to syngas (synthetic gas) and deoxidation from metal melts. Thus, various types of the oxygen permeation membrane (OPM) have been developed. The oxygen-permeating membranes (OPMs) developed to date are classified as three types. ${ }^{1)}$ The popular types are monophasic membrane and dual phase membrane, which exhibit a mixed ionic and electronic conductivity (MIEC). ${ }^{2-7)}$ In those membranes, the $\mathrm{O}^{2-}$ (oxygen ion) and $\mathrm{e}^{\prime}$ or $\mathrm{h} \cdot$ (electron or electron-holes) are chemically driven by the oxygen chemical potential gradient between both sides of the membranes without an external circuit. The two membranes have big advantages because they operate without expensive metal electrodes or electric devices for the current source. However, the surface-exchange reaction kinetics for oxygen permeation may be low due to a lack of novel electrode materials. Moreover, in the dual phase membrane, the

Corresponding author: Hee Jung Park

E-mail : parkjang@dankook.ac.kr

Tel : +82-41-550-3533 Fax : +82-41-559-7866

ORCID

http://orcid.org/0000-0001-8178-5345 chemical compatibility and mechanical stability between the metal phase and oxide phase needs to be satisfied for stability. On the other hand, an oxygen pump (or the amperometric membrane), the third type, consists of not MIEC but a solid electrolyte (SE) sandwiched between two gas-permeable, electrically conductive electrodes. ${ }^{8,9)}$ This type has an advantage in that the oxygen flux can be controlled by varying the applied potential even though expensive electrodes are necessary to provide the electronic conductivity. In addition, the oxygen permeation performance is very reliable due to using zirconia, which has mechanical and chemical stability. However, most studies and usage for the oxygen pump have been based on a combination of yttrium-doped zirconia (YSZ) as the SE and novel metals (Pt, Ag) as electrodes and focused on not the surface exchange kinetics but the bulk diffusion property of the oxygen pump. ${ }^{1,10,11)}$ Recently, studies on an OPM driven by electrical current with doped ceria as the SE and associated high performance electrodes such as Sr-doped $\mathrm{LaFeO}_{3}$ (LSF) and $\mathrm{La}_{1-\mathrm{x}} \mathrm{Sr}_{\mathrm{x}} \mathrm{Co}_{1-\mathrm{y}} \mathrm{Fe}_{\mathrm{y}} \mathrm{O}_{3}$ (LSCF) have been conducted and they have reported high oxygen permeation. ${ }^{9}$ It is known that doped ceria has higher oxygen ionic conductivity than YSZ, and LSCF also has a low polarization resistance as an electrode material. ${ }^{12-14)}$

In this study, we used scandium (Sc)-doped zirconia as a SE for an OPM driven by electrical current. The Sc-doped zirconia is another notable oxygen ionic conductor that comes close to doped ceria, which has an ionic conductivity 
almost an order of magnitude higher than YSZ. To maximize the oxygen permeation of the Sc-doped zirconia-based membrane with the composite electrode consisting of zirconia and doped-lanthanum manganate, we needed to apply enough current to the OPM. We thoroughly studied the electrode resistance of the composite related to the surface exchange kinetics for oxygen permeation and analyzed its impedance spectroscopy.

\section{Experimental Procedure}

Appropriate metal oxides were weighed to prepare codoped zirconia $\left(\mathrm{Zr}_{0.895} \mathrm{Sc}_{0.095} \mathrm{Ce}_{0.005} \mathrm{Gd}_{0.005} \mathrm{O}_{2-\delta}, \mathrm{ScCeGdZ}\right)$ as the SE of the OPM. We used a typical tape casting process and ceramic sintering process to fabricate a thin disk-type SE with a high density (relative density $>95 \%$ ). Zirconiaslurry was first prepared by mixing metal-oxide powders, a solvent (ethanol) and some functional materials (binders, plasticizer), and then the tape-casting process was performed to prepare thin zirconia sheets. Finally, we conducted a sintering process at $1420^{\circ} \mathrm{C}$ for $6 \mathrm{~h}$ in air after laminating the sheets and then isostatic pressing.

The OPM was finalized by electroding on the sintered zirconia disk with the composite electrode. The electrode compositions were LSM-80\%/ScCeGdZ-20\% (LZ82), LSM-50\%/ ScCeGdZ-50\% (LZ55) and LSM-30\%/ScCeGdZ-70\% (LZ37). As for the composite electrode, two commercial powders (Kceracell company) were mixed using an alumina mortar and pestle with an ink vehicle, and then the mixed paste was screen-printed on both sides of the zirconia. Lastly, the OPM with the composite electrode was thermally treated at $1100^{\circ} \mathrm{C}$ for $2 \mathrm{~h}$ in air. The thickness of the zirconia was $\sim 0.03 \mathrm{~cm}$ and the area of the electrode was $0.5 \mathrm{~cm}^{2}$.

The SE and electrode resistances of the OPM were investigated by Electrochemical Impedance Spectra (EIS) mea-

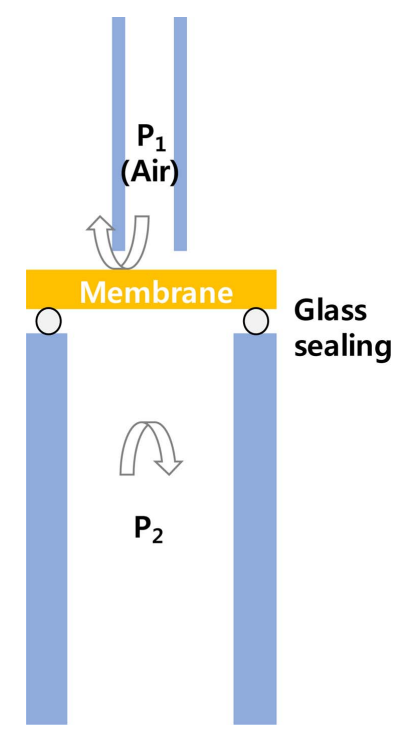

Fig. 1. A schematic diagram of the oxygen permeation test setup. surements using an impedance analyzer (SP-200, Biologics). The obtained EIS data were analyzed using Z-view software (Scribner Associates) to estimate the resistance $(R)$ of the sample. The EIS tests were conducted as a function of temperature $\left(750-850^{\circ} \mathrm{C}\right)$ under an oxygen permeation test setup. Ac impedance spectra were obtained in a frequency range of $0.5 \mathrm{~Hz}-5 \mathrm{MHz}$ at an amplitude of $30 \mathrm{mV}$. Fig. 1 shows a schematic diagram of the oxygen permeation setup. As seen, the upper side of the membrane $\left(\mathrm{P}_{1}\right.$, oxygen partial pressure in the upper side) was fixed as air with a flowrate of $\sim 100 \mathrm{cc} / \mathrm{min}$ and the lower side $\left(\mathrm{P}_{2}\right)$ was varied with pure oxygen $\left(\mathrm{O}_{2}\right)$, air and $1 \% \mathrm{O}_{2} / \mathrm{N}_{2}$-balance with the same flowrate. Glass sealing was applied and gas leakage was checked with a zirconia oxygen sensor. The oxygen permeation was generated by applying an electric current (0-1.8 $\mathrm{A} / \mathrm{cm}^{2}$ ) with Keithley Instruments (K237, K2400) and the permeated oxygen flux $\left(\mathrm{JO}_{2}\right)$ was calculated by analyzing the oxygen concentration $\left(\mathrm{Co}_{2}\right)$ at the permeated side $\left(\mathrm{P}_{2}\right)$ using a zirconia oxygen sensor. ${ }^{15)}$

\subsection{Background: bulk diffusion and surface-exchange kinetics}

It is known that the oxygen permeation process through the OPM consists of three steps, the bulk diffusion of oxygen ions, the rate of surface-exchange between molecular oxygen and oxygen ions, and the gas-solid mass transfer of gaseous oxygen. ${ }^{1)}$ Among them, the bulk diffusion of oxygen ions and the surface-exchange kinetics are important steps in determining the oxygen permeation flux of membranes. ${ }^{1,15)}$

In general, the oxygen flux by the bulk diffusion process can be given by

$$
J_{\mathrm{k}} \approx \sigma_{\mathrm{amb}} /\left(\mathrm{z}_{\mathrm{k}} F\right)^{2} \nabla \eta_{\mathrm{k}}
$$

where $J_{\mathrm{k}}$ is the charged particle flux, $\mathrm{z}$ is the charge number of the charge carrier $\left(\mathrm{O}^{2-}\right)$ and $\sigma_{\mathrm{amb}}$ is the ambipolar conductivity of the membrane $\left(\sigma_{\mathrm{amb}}=\sigma_{\mathrm{el}}{ }^{*} \sigma_{\text {ion }} /\left(\sigma_{\mathrm{el}}+\sigma_{\text {ion }}\right)\right.$, where $\sigma_{\mathrm{el}}$ is the electronic conductivity and $\sigma_{\text {ion }}$ the ionic conductivity, $F$ the Faraday constant, and $\nabla \eta_{\mathrm{k}}$ the gradient of the electrochemical potential, which is the driving force for the permeation of the particles (the electrochemical potential comprises a gradient in the chemical potential gradient $\nabla \mu_{\mathrm{k}}$ and a gradient in electrical potential $\nabla \phi)^{1{ }^{1}}$

A similar expression for surface-exchange kinetics, which is another important factor in determining the oxygen permeation flux, is given by

$$
J_{\mathrm{O} 2}=J_{\mathrm{ex}}{ }^{0} \nabla \eta_{\mathrm{O} 2}
$$

where $J_{\mathrm{ex}}{ }^{\mathrm{o}}$ denotes the balanced exchange rate in the absence of the electrochemical potential gradient. It is known that a balanced exchange rate highly relates to the oxygen-ion diffusion and electron transfer, which are important elementary steps in the overall oxygen oxidation/reduction reaction on the surface on oxygen permeation, which means that the ambipolar conduction is also an important factor in the balanced exchange rate. That is, the ambipolar 
conductions at both the membrane bulk and surface should be thoroughly considered for high oxygen permeation through the membrane. The overall reaction taking place on the surface is given by the following equation (Kröger-Vink notation was used). ${ }^{16)}$

$$
\mathrm{O}_{\mathrm{o}}{ }^{\mathrm{x}} \leftrightarrow 1 / 2 \mathrm{O}_{2}+\mathrm{V}_{\mathrm{o}} \cdot{ }^{\cdot}+2 e^{\prime}
$$

Considering both Eqs. (1) and (2), the oxygen permeability of the OPM is strongly related to the ambipolar conduction of the membrane bulk and the balanced exchange rate of the membrane surface.

In the electrochemical type OPM that uses a pure ionic conductor as the SE, ambipolar conduction of the membrane is controlled by the applied electric current. As is well known, Sc-doped $\mathrm{ZrO}_{2}$, the $\mathrm{SE}$ of the OPM in this study, is a pure ionic conductor. Thus, in principle, the oxygen ionic current through the zirconia membrane should be equivalent to the applied electrical current according to Faraday equation (note that it is valid when the ionic current is strong enough to be higher than the electronic one). ${ }^{9)}$

$$
\begin{aligned}
& \left.J_{\mathrm{O}_{2}}(\text { oxygen permeation flux, } \mathrm{mol} / \mathrm{sec})=I \text { (current, } \mathrm{A}\right) / \\
& F(\text { Faraday constant, } \mathrm{C} / \mathrm{mol})
\end{aligned}
$$

\section{Result and Discussion}

\subsection{X-ray diffraction and microstructures}

The zirconia-based OPMs were fabricated using the lanthanum manganate and zirconia composite as electrodes. Thermal treatment followed screen-printing of the composites on both sides of the zirconia. Fig. 2 shows the X-ray diffraction (XRD) patterns of the composite electrodes (LZ82, LZ55, LZ37). The detected patterns were indexed based on a physical mixture of the cubic zirconia phase and the LSM phase with a perovskite structure, indicating that no secondary phases were formed between them. The XRD patterns of the cubic zirconia powders and LSM powders were inserted for comparison.

Figure 3 shows a schematic diagram of the OPM and the microstructure of LZ55. As expected, the SE was almost fully dense and the electrode was highly porous. In addition, a good adhesion between the SE and the electrode was

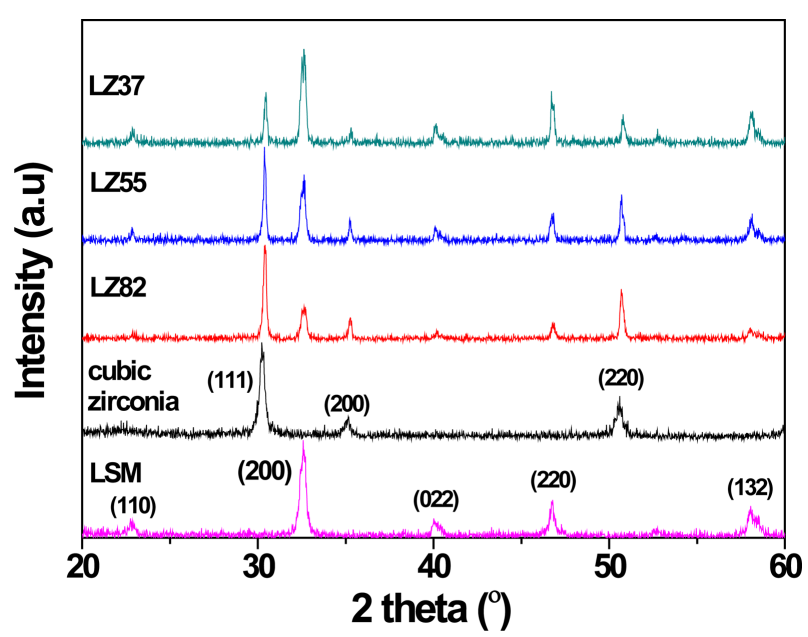

Fig. 2. X-ray diffraction patterns of the composite electrodes (LZ82, LZ55, LZ37) and those of the cubic zirconia and LSM powders for comparison.

achieved due to optimal thermal treatment $\left(1100^{\circ} \mathrm{C}\right.$ in air). The average thickness of the electrode was $\sim 15 \mu \mathrm{m}$.

\subsection{EIS study and oxygen permeation}

The high oxygen permeation flux is the most important factor for the oxygen permeation membrane. For oxygen to permeate through the membrane from the feed side to the permeate side, as mentioned previously, the oxygen transport through the membrane (bulk diffusion) and the surface oxygen-exchange rate on both sides of the membrane (surface-exchange kinetics) are important for the oxygen permeation because the gas-solid mass transfer is fast enough to be ignored. Accordingly, if the surface-exchange kinetics is much faster than the bulk-diffusion, the oxygen permeation rate is controlled by the bulk-diffusion (bulk diffusion limit), and if reversed, it is governed by the surface exchange kinetics (surface-exchange kinetics limit). Thus, high surface-exchange kinetics should be made in order to obtain the maximum oxygen permeation by the lattice diffusion of oxygen ions through the membrane. ${ }^{1,2,4)}$ It is known that fast kinetics is realized at a low electrode resistance for oxygen reduction/oxidation reactions in the surface of the mem-

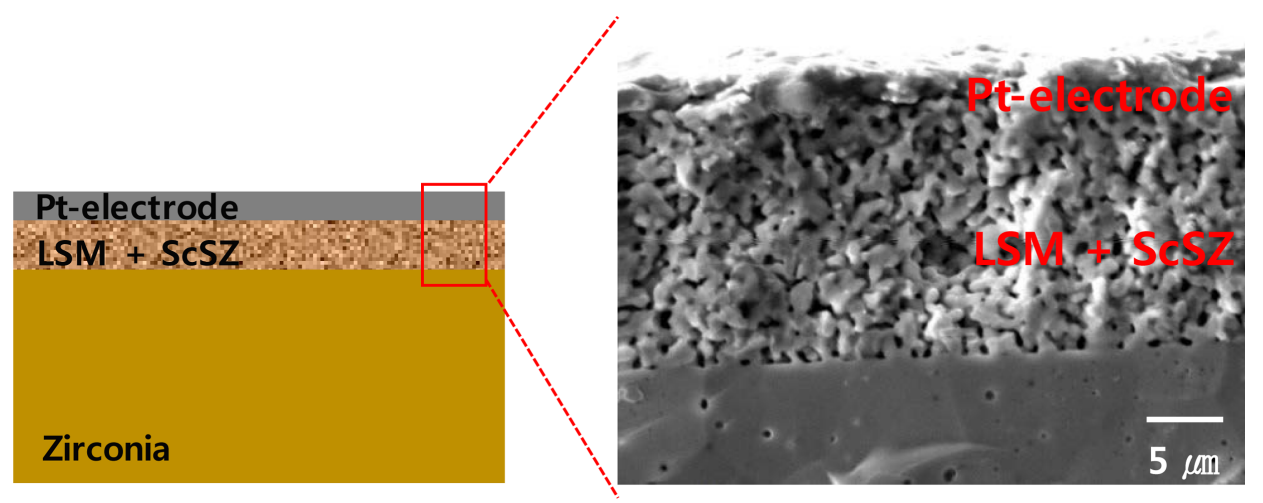

Fig. 3. SEM photographs of the zirconia SEs and composite electrodes. (a) LZ82, (b) LZ55 and (c) LZ37. 


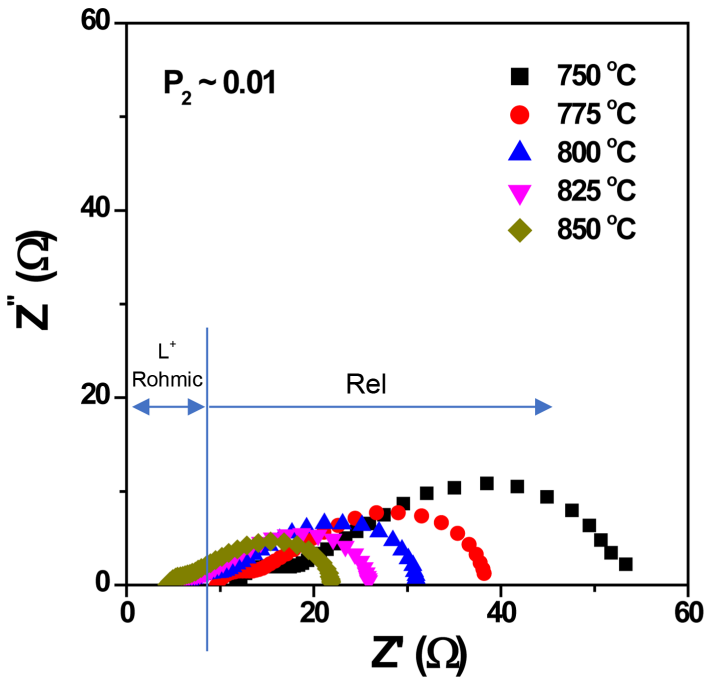

(a)

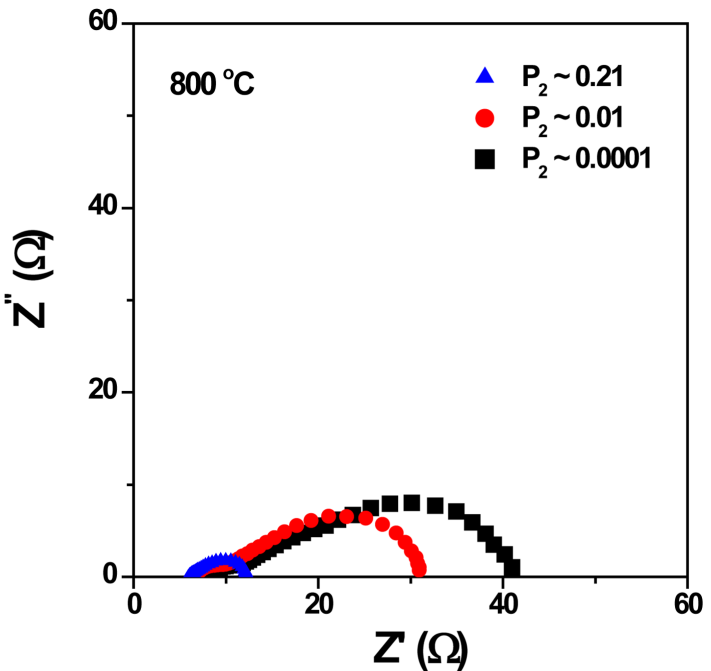

(b)

Fig. 4. The impedance spectra of OPM with LZ82 measured at different temperatures in $\mathrm{P}_{2} \sim 0.01$ atm. $R_{\text {ohmic }}$ and $R_{\text {el }}$ are the ohmic resistance and the electrode resistance of the OPM. $L$ is the inductance.

brane..$^{4,16)}$

We investigated the electrochemical properties (electrode and electrolyte resistances) of OPMs using 2-p ac impedance spectroscopy as a function of temperature and various $\mathrm{P}_{2}$ conditions. Fig. 4(a) shows representative impedance spectra (i.e., a Nyquist plot) of the OPM with LZ82 measured at different temperatures in $\mathrm{P}_{2} \sim 0.01 \mathrm{~atm}$. As indicated in the figure, the left offset of the semicircular arc (cross point to the left of the semicircular and the x-axis) is the sum of the inductance $(L)$ and ohmic resistance $\left(R_{\text {ohmic }}\right)$ and the right offset (cross point to the right of the semicircular and the x-axis) is the electrode polarization resistance $\left(R_{e l}\right)$ of the cell. It is known that most $R_{\text {ohmic }}$ values are due to the electrolyte resistance $\left(R_{S E}\right)$ even though there are some other reasons, such as electrode ohmic resistance (note that the dominant charge carrier of doped zirconia is the oxygen ion). ${ }^{17)}$ As seen, the high-frequency offsets slightly move in the direction of the zero point with an increasing temperature, which may be due to the large contribution of the oxygen ionic conduction of the SE. On the other hand, $R_{e l}$ significantly decreases with an increasing temperature (note that the imperfect semicircular arcs correspond to $R_{e l} \mathrm{~S}$ ), for example, $R_{e l} \sim 17 \mathrm{ohm}$ at $850^{\circ} \mathrm{C}$ and $\sim 45 \mathrm{ohm}$ at $750^{\circ} \mathrm{C}$. $R_{e l}$ also depends on $\mathrm{P}_{2}$, which increases at a low $\mathrm{P}_{2}$ (Fig. 4(b), note the increased $R_{e l}$ at a low $\mathrm{P}_{2}$ is due to the $\mathrm{P}_{2}$ side (permeated side) since $\mathrm{P}_{1}$ is all the same as air). The depression of the arcs is known to be due to multiple reactions involved in the polarization process of the electrode. ${ }^{16,18)}$

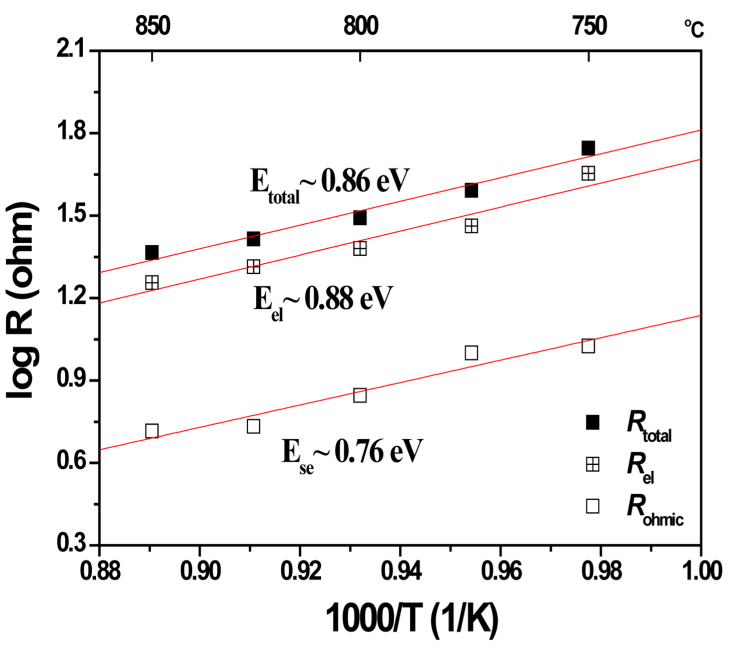

(a)

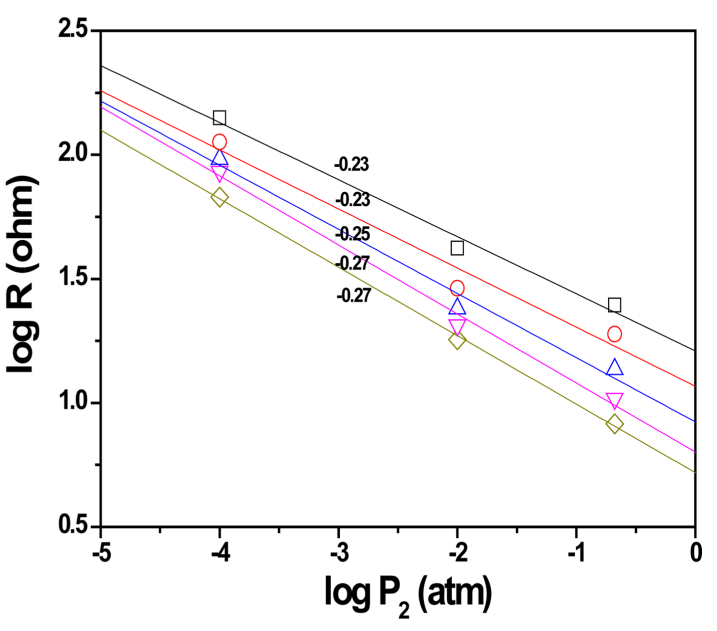

(b)

Fig. 5. (a) The temperature dependence of $R_{\text {ohmic }}, R_{e l}$ and $R_{\text {total }}$ in OPM with LZ82 and (b) the $\mathrm{P}_{2}$ dependence of $R_{\mathrm{p}}$ (slope :- 0.23 , $-0.23,-0.25,-0.27,-0.27$ for $\square, \bigcirc, \triangle, \nabla, \diamond$ respectively). 
The temperature dependence of $R_{\text {ohmic }}, R_{e l}$ and $R_{\text {total }}\left(R_{\text {ohmic }}\right.$ $\left.+R_{e l}\right)$ is shown in Fig. 5(a). All resistances decreased with an increasing temperature. Using numerical linear fitting, the activation energies $\left(\mathrm{E}_{\mathrm{a}} \mathrm{s}\right)$ of the resistances were computed to be $\sim 0.76 \mathrm{eV}$ ( $\mathrm{E}_{\text {ohmic }}$ of $\left.R_{\text {ohmic }}\right), \sim 0.88 \mathrm{eV}\left(\mathrm{E}_{\text {el }}\right.$ of $\left.R_{e l}\right)$ and $\sim 0.86 \mathrm{eV}\left(\mathrm{E}_{\mathrm{total}}\right.$ of $\left.R_{\text {total }}\right)$. As seen in the figure, $\mathrm{E}_{\text {ohmic }}$ was close to the activation energy of the oxygen ionic conduction of Sc-doped zirconia, making sure that $R_{\text {ohmic }}$ originated from the $\mathrm{SE}$ resistance. ${ }^{17)} \mathrm{E}_{\mathrm{el}}$ was higher than $\mathrm{E}_{\text {ohmic }}$, and $\mathrm{E}_{\text {total }}$ followed $\mathrm{E}_{\mathrm{el}}$ because $R_{e l}$ was much higher than $\mathrm{R}_{\text {ohmic }}$. Considering that LSM is highly conductive (metal conduction behavior, note that most of the composition in LZ82 is LSM), we concluded that the observed $\mathrm{E}_{\mathrm{el}} \sim 0.88 \mathrm{eV}$ originated not from the ohmic resistance of the electrode but from the polarization resistance of the electrode $\left(R_{\mathrm{p}}\right.$, especially $R_{\mathrm{p}}$ in $\left.\mathrm{P}_{2} . R_{\mathrm{p}} \approx R_{\mathrm{el}}\right)$. ${ }^{16)}$ The origin of $R_{\mathrm{p}}$ can be revealed through a $\mathrm{Po}_{2}$-denpedence study, although the polarization reaction is very complex. It is known that the whole polarization reaction involves many elementary reactions, such

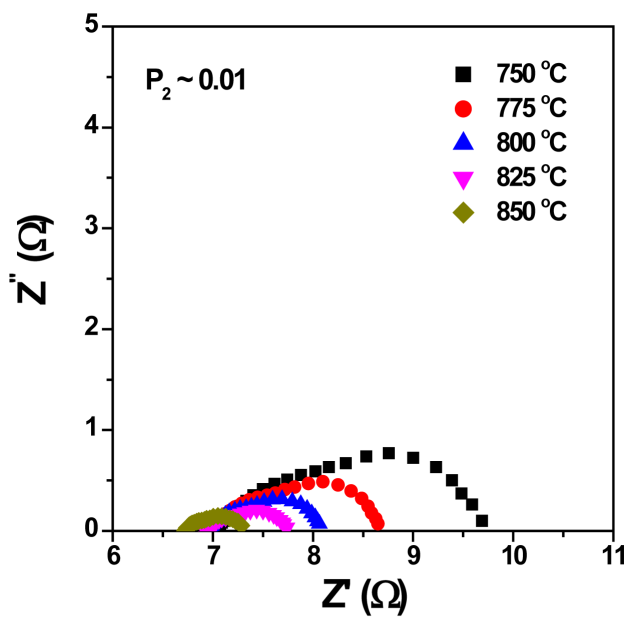

(a)

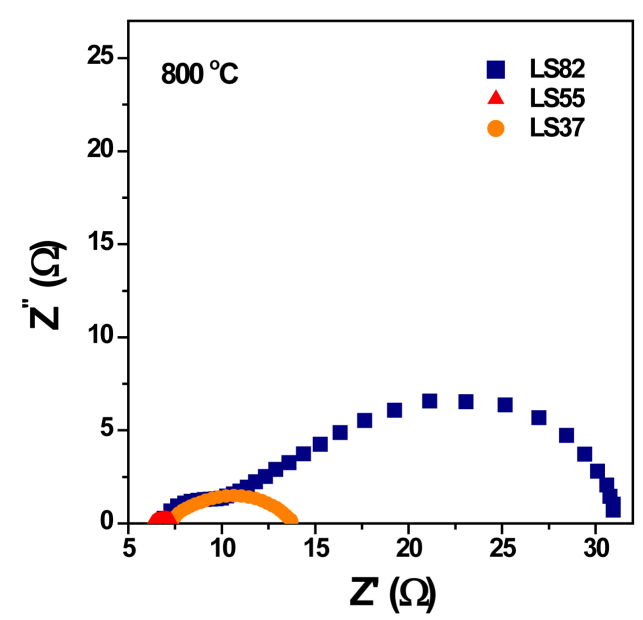

(c) as the diffusion of charge carrier species (oxygen ions and electrons), gas diffusion, absorption and desorption, and ionic incorporation. ${ }^{16)}$ Fig. 5(b) shows the $R_{\mathrm{p}}$ at various values of $\mathrm{P}_{2}$. As seen, the resistance depends on the - 1/4 exponent of $\mathrm{P}_{2}$, which means that the polarization origin is slow oxygen-ionic diffusion in the surface reaction. Thus, in order to enhance the electrode performance, electrode materials should have a high oxygen ionic conduction. (Note that LSM in LZ82, the electronic phase, is the main phase so the zirconia, the ionic conducting phase, is not enough to make a percolation of the oxygen ionic diffusion.) A simple way to enhance the oxygen ionic diffusion on the surface is to increase the amount of zirconia in the electrode. Such a strategy is very close to that for a high performance electrode of solid oxide fuel cells. ${ }^{18,19)}$

Figures 6(a) and (b) exhibit the impedance spectra of OPM with LZ55 and LZ37 measured at different temperatures in $\mathrm{P}_{2} \sim 0.01 \mathrm{~atm}$. The $R_{e l} \mathrm{~S}$ of LZ55 and LZ37 decreased while the $R_{\text {ohmic }} \mathrm{S}$ values were similar to the $R_{\text {ohmic }}$ of LZ82. In par-

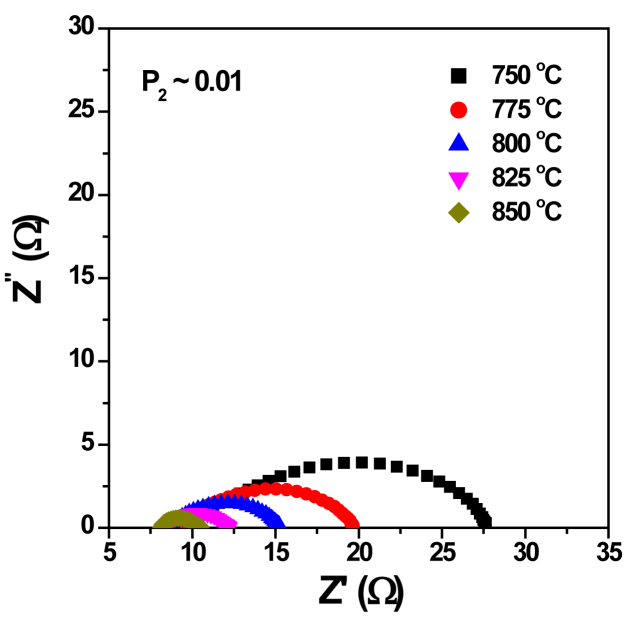

(b)

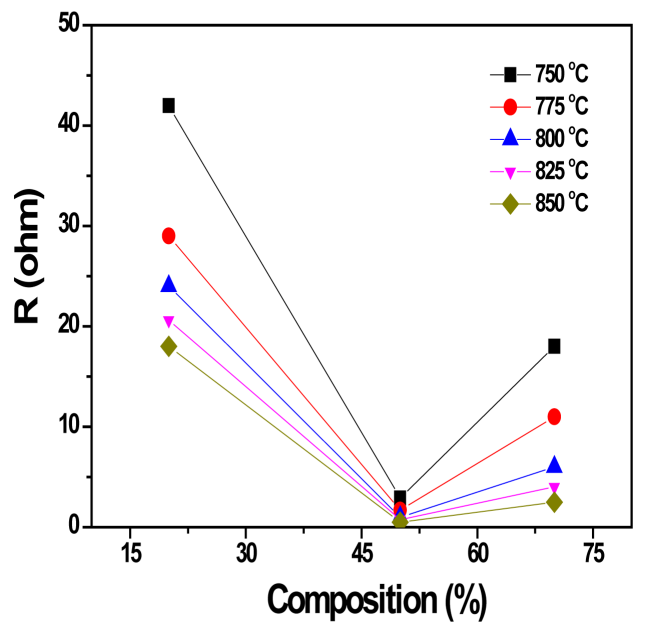

(d)

Fig. 6. The impedance spectra of the OPM with (a) LZ55 and (b)LZ37 measured at different temperatures in $\mathrm{P}_{2} \sim 0.01$ atm. (c) A comparison of the impedance patterns of the OPM with LZ82, LZ55 and LZ37 at $800^{\circ} \mathrm{C}$ and $\mathrm{P}_{2} \sim 0.01 \mathrm{~atm}$. (d) A comparison for all the measured temperatures as a function of the amount of the zirconia. 
ticular, the $R_{e l}$ of LZ55 significantly decreased as expected. Even though the data measured at different values of $\mathrm{P}_{2}\left(\mathrm{P}_{2}\right.$ $\sim 0.21 \mathrm{~atm}$ and $0.0001 \mathrm{~atm})$ are not shown here, the tendency of $R_{e l}$ mostly decreasing in LZ55 is the same. In strategy, increasing the amount of the zirconia might enhance the oxygen ionic diffusion in the electrode and thus improve the surface-exchange kinetics. Fig. 6(c) compares the impedance spectra of all the samples obtained at $800^{\circ} \mathrm{C} . R_{e l}$ in LZ55 decreased to $\sim 1 \mathrm{ohm}$ at that temperature. The comparison for all measured temperatures as a function of the amount of zirconia is shown in Fig. 6(d). At all measured temperature, the LZ55 electrode shows the lowest electrode resistance, implying that the best electrode material among the tested samples is LZ55. As mentioned above, the lower the polarization resistance, the better (or the faster) the surface-exchange kinetics in the OPM. Thus the OPM with LZ55 likely shows the high performance because of the oxygen permeation.

Figure 7(a) exhibits the oxygen permeation flux $\left(\mathrm{JO}_{2}\right)$ in the OPM with LZ55 as a function of the applied current (0$1.8 \mathrm{~A} / \mathrm{cm}^{2}$ ). In the region below $1.2-1.4 \mathrm{~A} / \mathrm{cm}^{2}, \mathrm{Jo}_{2}$ constantly increased with the applied current, suggesting that the oxygen permeation was mainly controlled by the applied current. However, it became saturated over a certain applied current as seen. As described previously, $\mathrm{JO}_{2}$ depends on the ambipolar conduction of the membrane (see Eqs. (1) and (2)). Considering the zirconia SE, oxygen ionic conduction is dominant and electronic conduction minor so that the ambipolar conduction is mainly determined by the electronic conduction. Under those conditions, supplying electrons by applying current proportionally increases the electronic portion, which increases the ambipolar conduction, which is the reason $\mathrm{JO}_{2}$ increases as the current increases. However, applying more a certain value makes the electronic conduction dominant, which creates a situation in which the oxygen ionic conduction becomes a bottle-neck for oxygen permeation $\left(\sigma_{\text {ion }}<\sigma_{\text {el }}\right)$. Under this condition, $\mathrm{JO}_{2}$ no longer increases because the oxygen ionic conduction of the OPM has a specific value depending only on the operation temperature, and the value (the oxygen ionic conductivity) is nearly unchanged as the applied current. The black solid line in Fig. 7(a) indicates the theoretical value computed using Eq. (4) (Faraday equation). The data measured at $825^{\circ} \mathrm{C}$ and $850^{\circ} \mathrm{C}$ agree well with the theoretical value under $\sim 1.4 \mathrm{~A} / \mathrm{cm}^{2}$ because the oxygen ionic conductivity is sufficient to be high enough for ambipolar conduction. On the other hand, the measured $\mathrm{JO}_{2} \mathrm{~S}$ below $800^{\circ} \mathrm{C}$ are slightly lower than the solid line because of insufficient ionic conduction. The saturated values are also smaller at lower temperatures because the ionic conductivity is lower than at higher temperatures. The maximum $\mathrm{JO}_{2} \mathrm{~S}$ at $850^{\circ} \mathrm{C}$ and $750^{\circ} \mathrm{C}$ are $\sim 3.5 \times 10^{-6} \mathrm{~mol} / \mathrm{cm}^{2} \mathrm{~s}$ in I $=1.4 \mathrm{~A} / \mathrm{cm}^{2}$ and $\sim 1.9 \mathrm{~mol} /$ $\mathrm{cm}^{2} \mathrm{~s}$ in $\mathrm{I}=1.2 \mathrm{~A} / \mathrm{cm}^{2}$. Owing to the fact, the Faraday efficiency is higher at elevated temperatures as seen in Fig. 7(b). For example, it was $\sim 99 \%$ at $825^{\circ} \mathrm{C}$ and $850^{\circ} \mathrm{C}$ in $1 \mathrm{~A} /$ $\mathrm{cm}^{2}$. More applied current decreases the efficiency.

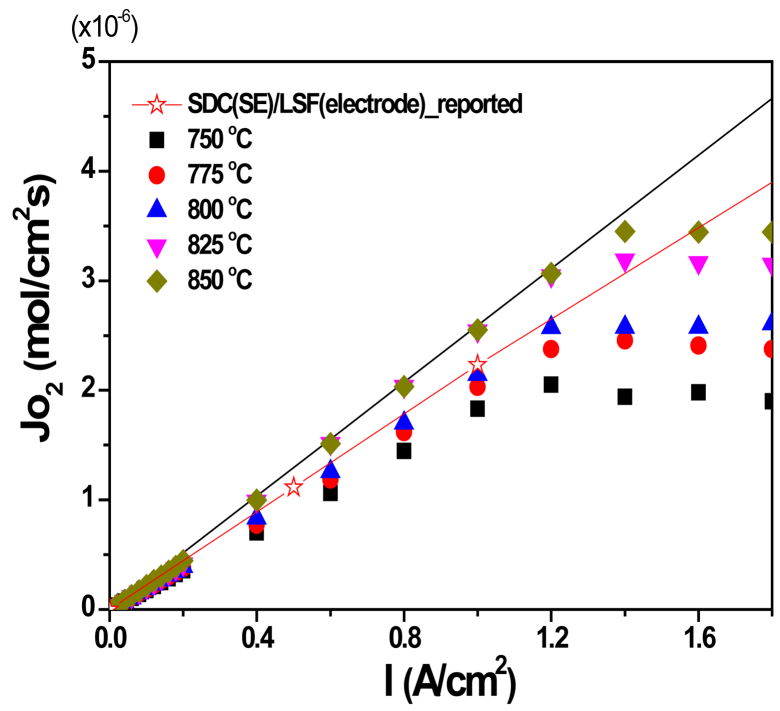

(a)

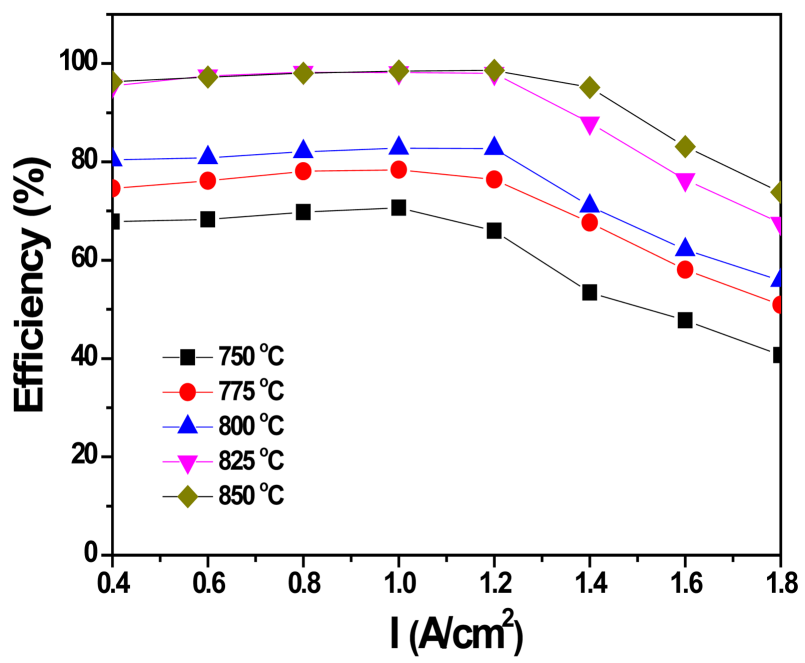

(b)

Fig. 7. (a) The oxygen permeation flux in the OPM with LZ55 as a function of the applied current $(0 \sim 1.8 \mathrm{~A} /$ $\mathrm{cm}^{2}$ ). The black solid line is the theoretical prediction by Faraday's Law. (b) the Faraday efficiency at various temperatures.

In order to compare with our oxygen permeation performance with that of others, we inserted the reported value in Fig. 7(a). The open-star symbols exhibit the performance of the OPM consisting of the Sm-doped $\mathrm{CeO}_{2}$ (SDC) SE and the Sr-doped $\mathrm{LaFeO}_{3}$ (LSF) electrode with a very high oxygen ionic conduction and low polarization resistance. We thought the value slightly lower than the theoretical value in the SDC/LSF system was due to the generation of the electronic conduction of the ceria SE. As seen, regardless of the reason, our oxygen permeation is a little higher than that or in a similar range, proving that the OPM with LZ55 in this study is also a good oxygen permeable membrane. (Note that the SDC-LSF system is a very competitive OPM in light of its oxygen permeation value.) 


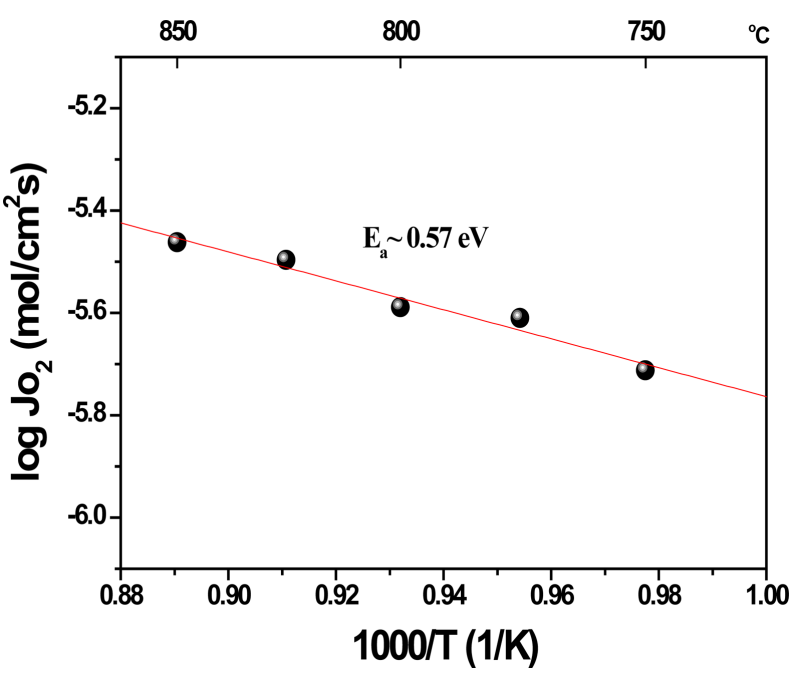

Fig. 8. The saturated values of the oxygen permeation flux at different temperatures.

The saturated values in Fig. 7(a) were plotted as a function of temperature (Arrhenius plot, Fig. 8). The estimated activation energy was $\sim 0.57 \mathrm{eV}$ and it is likely that the oxygen permeation is affected by the oxygen ionic conduction of Sc-doped $\mathrm{ZrO}_{2}\left(\mathrm{E}_{\mathrm{a}}\right.$ of the oxygen ionic conduction is in a range of $0.7-0.8 \mathrm{eV}){ }^{17,20,21)}$

\section{Conclusions}

Oxygen permeating membranes (OPM) consisting of a $\mathrm{Zr}_{0.895} \mathrm{Sc}_{0.095} \mathrm{Ce}_{0.005} \mathrm{Gd}_{0.005} \mathrm{O}_{2-\delta} \quad(\mathrm{ScCeGdZ}$, solid electrolyte)/ aLa ${ }_{0.7} \mathrm{Sr}_{0.3} \mathrm{MnO}_{3}$-bScCeGdZ composite (LZab, electrode) were designed to generate pure oxygen. Their electrical properties were investigated using 2-p ac impedance spectroscopy. The results confirmed that LZ55 had the lowest electrode resistance among LZ82, LZ55 and LZ37. The OPM with LZ55 experienced an increased oxygen flux as the applied current up to a certain current and the saturated OPM with more applying. This behavior of the oxygen flux for the applied current was explained considering the ambipolar conduction of the membrane. The OPM with LZ55 exhibited $\sim 3.5 \times 10^{-6} \mathrm{~mol} / \mathrm{cm}^{2} \mathrm{~s}$ in $\mathrm{I}=1.4 \mathrm{~A} / \mathrm{cm}^{2}$ and also demonstrated high Faraday efficiency for oxygen permeation. It reached $\sim 99 \%$ under $1 \mathrm{~A} / \mathrm{cm}^{2}$ at elevated temperatures.

\section{Acknowledgments}

This work was supported by the Korea Institute of Energy Technology Evaluation and Planning (KETEP) and the Ministry of Trade, Industry \& Energy (MOTIE) of the Republic of Korea (No. 20152020105950). We are greatly indebted to H.C. Shin for the zirconia fabrication.

\section{REFERENCES}

1. P. J. Gellings and H. Bouwmeester, The CRC Handbook of Solid State Electrochemistry; pp. 428-59, CRC Press, 1997.

2. H. J. Park and G. M. Choi, "The Effect of Surface Coating on the Oxygen Permeation Characteristics of Zirconia," J. Eur. Ceram. Soc., 25 [12] 2577-81 (2005).

3. H. J. Park, J. K. Yang, Y. H. Jin, and K. H. Lee, "The Oxygen-Permeation Property of Doped-Zirconia Membrane at High Temperature and in Reduced Condition," Int. J. Hydrogen Energy, 43 [14] 293-300 (2018).

4. H. J. Park and G. M. Choi, "Oxygen Exchange and Transport Properties of Yttria-Stabilized Zirconia Coated with $\mathrm{LaCrO}_{3}$, , J. Electroceram., 17 781-86 (2006).

5. M. Salehi, F. Clemens, E. M. Pfaff, S. Diethelm, C. Leach, T. Graule, and B. Grobety, "A Case Study of the Effect of Grain Size on the Oxygen Permeation Flux of BSCF DiskShaped Membrane Fabricated by Thermoplastic Processing," J. Membrane Sci., 382 [2-4] 186-93 (2011).

6. S. Li, W. Jin, N. Xu, and J. Shi, "Synthesis and Oxygen Permeation Properties of $\mathrm{La}_{0.2} \mathrm{Sr}_{0.8} \mathrm{Co}_{0.2} \mathrm{Fe}_{0.8} \mathrm{O}_{3-\delta}$ Membranes," Solid State Ionics, 124 [1-2] 161-70 (1999).

7. J. Kim and Y. S. Lin, "Synthesis and Oxygen Permeation Properties of Ceramic-Metal Dual-Phase Membranes," J. Membrane Sci., 167 [1] 123-33 (2000).

8. A. Krishnan, X. G. Lu, and U. B. Pal, "Solid Oxide Membrane (SOM) Technology for Environmentally Sound Production of Tantalum Metal and Alloys from their Oxide Sources," Scand. J. Metall., 34 [6] 293-301 (2005).

9. K. Zhang, B. Meng, X. Tan, L. Liu, S. Wang, and S. Liu, " $\mathrm{CO}_{2}$-Tolerant Ceramic Membrane Driven by Electrical Current for Oxygen Production at Intermediate Temperatures," J. Am. Ceram. Soc., 97 [1] 120-26 (2014).

10. J. Milshtein, E. Gratz, S. Pati, A. C. Powell, and U. Pal, "Yttria-Stabilized Zirconia Membrane Stability in Molten Fluoride Fluxes for Low-Carbon Magnesium Production by the SOM Process," J. Min. Metall., Sect. B, 49 [2] 18390 (2013).

11. R. Ramamoorthy, P. K. Dutta, and S. A. Akbar, "Oxygen Sensors: Materials, Methods, Designs, and Applications," J. Mater. Sci., 38 [21] 4271-82 (2003).

12. H. J. Park and J. Y. Park, "A Promising High Performance Lanthanum Ferrite-based Composite Cathode for Intermediate Temperature Solid Oxide Fuel Cells (SOFCs)," Solid State Ionics, 244 30-4 (2013).

13. F. Tietz, V. A. C. Haanappel, A. Mai, J. Mertens, and D. Stover, "Performance of LSCF Cathodes in Cell Tests," J. Power Sources, 156 [1] 20-2 (2006).

14. C. Kwak, D. W. Jung, D. H. Yeon, J. S. Kim, H. J. Park, S. J. Ahn, S. Y. Seo, and S. M. Lee, "Stabilization of HighCobalt-Content Perovskites for Use as Cathodes in Solid Oxide Fuel Cells," RSC Adv., 3 [27] 10669-72 (2013).

15. H. J. Park and G. M. Choi, "Oxygen Permeation Characteristics of Zirconia with Surface Modification," Solid State Ionics, 177 [26-32] 2261-67 (2006).

16. H. J. Park, C. Kwak, J. S. Kim, and S. J. Ahn, "Electrochemical Properties of Pure $\mathrm{Ba}_{0.5} \mathrm{Sr}_{0.5} \mathrm{Co}_{0.8} \mathrm{Fe}_{0.2} \mathrm{O}_{3}$ and $\mathrm{Ba}_{0.5} \mathrm{Sr}_{0.5} \mathrm{Co}_{0.8} \mathrm{Fe}_{0.2} \mathrm{O}_{3}$-based Composite Cathodes for an Intermediate Temperature Solid Oxide Fuel Cell with Scdoped Zirconia Solid Electrolyte,” J. Power Sources, 213 31-9 (2012). 
17. C. Haering, A. Roosen, H. Schichl, and M. Schnoller, "Degradation of the Electrical Conductivity in Stabilised Zirconia System: Part II: Scandia-Stabilised Zirconia," Solid State Ionics, 176 [3-4] 261-68 (2005).

18. H. J. Park and S. Kim, "Electrochemical Characteristics of ZnO-Nanowire/Yttria-Stabilized Zirconia Composite as a Cathode for Solid Oxide Fuel Cells," Electrochem. SolidState Lett., 10 [11] B187-90 (2007).

19. D. W. Jung, C. Kwak, H. J. Park, J. S. Kim, S. J. Ahn, D. H. Yeon, S. Y. Seo, K. S. Moon, and S. M. Lee, "High-Performance Perovskite $\mathrm{Ba}_{0.5} \mathrm{Sr}_{0.5} \mathrm{Co}_{0.8} \mathrm{Fe}_{0.1} \mathrm{Zn}_{0.1} \mathrm{O}_{3^{-}}$
$\mathrm{La}_{0.6} \mathrm{Sr}_{0.4} \mathrm{Co}_{0.2} \mathrm{Fe}_{0.8} \mathrm{O}_{3}$ Composite Cathode," Scr. Mater., 113 59-62 (2016).

20. J. W. Fergus, "Electrolytes for Solid Oxide Fuel Cells," J. Power Sources, 162 30-40 (2006).

21. D. A. Agarkov, M. A. Borik, V. T. Bublik, S. I. Bredikhin, A. S. Chislov, A. V. Kulebyakin, I. E. Kuritsyna, E. E. Lomonov, F. O. Milovich, V. A. Myzina, V. V. Osiko, and N. Y. Tabachkova, "Structure and Transport Properties of Melt Grown $\mathrm{Sc}_{2} \mathrm{O}_{3}$ and $\mathrm{CeO}_{2}$ Doped $\mathrm{ZrO}_{2}$ Crystals," Solid State Ionics, 322 24-9 (2018). 